Die bei den angefïhrten Reactionen eintretenden Zersetzungen hat Verfasser näher studirt, doch kann hier im Allgemeinen wohl nur auf die betreffenden Original-Angaben verwiesen werden. Interessant sind jedoch die Ausführungen Eber's über das bei Zersetzung des Physostigmins häufig beobachtete, z. B. beim Kochen einer nentralen Physostigmin-Lösung entstehende inactive Physostigmin. Von dem Physostigmin unterscheidet sich dieser Körper durch folgende sehr dentliche und empfindliche Reactionen: Eine ammoniakalische Chlorsilberlösung wird sofort stark gebräunt.

Wird ein Tropfen einer inactiven Physostigminlösung mit 1 Tropfen Gerbsäurelösung vermischt, so verursachen Bromdämpfe vorübergehend eine blaugrüne Färbung. Die Bromeinwirkung wird am besten in der Weise bewerkstelligt, dass in die Nähe des Alkaloid-Gerbsäturegemisches ein Tropfen Bromwasser gebracht wird. Die Farbenveränderung tritt dann an der dem Brom zugewandten Seite deutlich auf.

Da das inactive Physostigmin in den gewöhnlichen Medizinaldosen des Physostigmins nicht ähnlich dem letzteren wirkt, so dürfte der Nachweis desselben in käuflichen Physostigminsalzen von Wichtigkeit sein. Insbesondere würde derselbe za versuchen sein, sobald die Lösungen derselben sich bereits kurz nach ihrer Anfertigung röthen.

\title{
V. Atom- und Aequivalentgewichte der Elemente.
}

$$
\text { Von }
$$

\section{W. Freseniu.s.}

Das Atomgewicht des Siliciums ist von T. E. Thorpe und J. W. Young*) neu bestimmt worden. Die Verfasser heben hervor, dass alle bis jetzt ausgefuhrten Bestimmungen nur auf der Feststellung des Verhältnisses von Chlor, respective Chlorsilber, zu Siliciumtetrachlorid beruhen, und dass von jedem Forscher nur wenige Versuche mit kleinen Substanzmengen angestellt worden seien.

Pelouze fand (bezogen auf $\mathrm{H}=1$ ) 28,35 and 28,86. Dumas fand 27,95 und 28,11 und Schiel erhielt 27,83 und 28,07 nach dieser Methode.

*) Journal of the chernical society $\mathbf{5 1 , 5 7 6 .}$ 
Die Verfasser wählten zu ibren Versuchen das Siliciumtetrabromid und bestimmten die Menge von Kieselsäure, welche man beim Zersetzen desselben mit Wasser erhält.

Sie stellten zu diesem Zweck etwa $1 / 2 \mathrm{~kg}$ des Tetrabromids her, indem sie einen Strom von Bromdampf über eine stark erhitzte Mischung von reiner Kieselsäure und fein gepulverter Weidenholzkohle, wie sie bei der Schiesspulverfabrikation benutzt wird, leiteten. Die Mischung von Kieselsäure und Kohle wurde in der Art hergestellt, dass die sehr fein gepulverten Bestandtheile innigst mit einander gemengt wurden, worauf man das Pulver mit Oel zu einer plastischen Masse anrieb, daraus Kugeln formte und diese in einem bedeckten Tiegel ausglühte. Die Kugeln wurden in einem weiten Porzellanrohr lose an einander gelegt und unter Erhitzen in einem Cokesofen dem Bromdampfstrom ausgesetzt. Das viel überschüssiges Brom enthaltende Product wurde in einem ganz aus Glas bestehenden Apparate, dessen einzelne Theile entweder an einander geschmolzen, oder in einander eingeschliffen waren, rectificirt. Hierauf wurde die Flüssigkeit mit Quecksilber geschüttelt, davon abdecantirt und mehrere Wochen lang mit Blattkupfer in Berührung gebracht, worauf sie im trockenen Stickstoffstrom destillirt wurde. Das so erhaltene Tetrabromid war eine völlig klare und farblose Flüssigkeit von dem constanten Siedepunkte $153^{\circ} \mathrm{C}$.

Die zur Analyse benutzten Portionen wurden in gleicher Weise in Glaskugeln aufgefangen, wie dies Thorpe bei der Atomgewichtsbestimmung des Titans ausgeführt hat.*)

Die mit der abgewogenen Substanzmenge gefüllten Kügelchen wurden mit etwa dem zehnfachen Gewicht Wasser in einer wohl verstopften Flasche geschüttelt, bis sie zerbrochen waren. Hierauf wurde die trübe Flüssigkeit in einen tarirten Tiegel decantirt und auf dem Wasserbade eingedampft, während in dem als Tara dienenden Tiegel ein gleiches Volumen Wasser verdampft wurde. Das Auswaschen der Flasche nebst den in derselben zurückbleibenden Glasstücken, sowie das Eindampfen des Wassers dauerte etwa eine Woche. Hierauf wurde der Tiegel mit Inhalt in einem Luftbade allmählich bis auf $160^{\circ} \mathrm{C}$. und dann noch einige Zeit in einer Muffel zur hellen Rothgluth erhitzt und gewogen.

Nachstehende Tabelle enthält die auf den luftleeren Raum reducirten Werthe der einzelnen Bestimmungen, bei denen zur Berechnung

*) Verg1 diese Zeitschrift 25, 293. 
die von Lothar Meyer and Karl Seubert angenommenen Atomgewichte für $\mathrm{H}, \mathrm{O}$ und $\mathrm{Br}$ benutzt wurden.

\begin{tabular}{c|c|c}
\hline $\begin{array}{c}\text { Angewandt } \\
\mathrm{Si} \mathrm{Br}_{4}\end{array}$ & $\begin{array}{c}\text { Erhalten } \\
\mathrm{Si} \mathrm{O}_{2}\end{array}$ & $\begin{array}{c}\text { Atomgewicht } \\
\text { des Si } \\
(0=15,96)\end{array}$ \\
\hline 9,63007 & $g$ & 28,347 \\
12,36099 & 1,67070 & 28,303 \\
12,98336 & 2,14318 & 28,347 \\
9,02269 & 2,25244 & 28,352 \\
15,38426 & 1,56542 & 28,243 \\
9,74550 & 2,66518 & 28,325 \\
6,19159 & 1,69020 & 28,429 \\
9,51204 & 1,07536 & 28,366 \\
10,69317 & 1,65065 & 28,364 \\
\hline 95,52367 & 1,85555 & gibt $\mathbf{2 8 , 3 3 2}$ \\
\hline
\end{tabular}

Die Verfasser hatten auch die Absicht, die gebildete Bromwasserstoffsäure zu bestimmen, gelangten aber bei Vorversuchen nicht zu befriedigenden Resultaten, so dass sie diese Bestimmungen nicht ausführten.

Das Atomgewicht des 0smiums hat $\mathrm{K}$ arl $\mathrm{Se}$ e bert*), veranlasst durch theoretische Gründe, neu bestimmt, zumal da bis jetzt nur zwei ältere Werthe (Berzelius 198,6 und Frémy 199,2) vorlagen, während ein von Berzeli us erhaltener dritter Werth, den er jedoch nicht bei der definitiven Atomgewichtsbestimmung benutzte, nur 195 ist.

Der Verfasser benutzte die Kalium- und Ammoniumdoppelchloride des Osmiums zur Untersuchning und bestimmte in ersterem den Gehalt an Osmium, Chlorkalium und Chlor, in letzterem den Gehalt an Osmium und Chlor.

Die Analysen wurden nach der bei der Bestimmung des Platinatomgewichtes von dem Verfasser befolgten Methode durch Glühen im Wasserstofistrome etc. ausgeführt.**)

Da der Verfasser die Arbeit als noch nicht abgeschlossen bezeichnet und ausführlichere Angaben in Aussicht stellt, sehe ich von einer Be-

*) Ber. d. deutsch. chem. Gesellsch. zu Berlin 21, 1839; vom Verfasser eingesandt.

**) Vergl. diese Zeitschrift 21, 165 . 